ERRATA

Ciênc. e Tecnol. Aliment, Campinas, 24 (3): 427-430 jul.-set. 2004

- Titularidade do autores:

\title{
RESSONÂNCIA PARAMAGNÉTICA ELETRÔNICA-RPE APLICADA À ANÁLISE DE ESPECIARIAS IRRADIADAS (COM RADIAÇÃO GAMA)
}

Alexandre Soares LEAL ${ }^{2, *}$, Klaus KRAMBROCK ${ }^{3}$, Kassilio GUEDES ${ }^{3}$, Rogério Rivail RODRIGUES ${ }^{2}$

\footnotetext{
1. Recebido para publicação em 11/07/2003. Aceito para publicação em 05/07/2004 (001167).

2. Centro de Desenvolvimento de Tecnologia Nuclear-CDTN/Comissão de Energia Nuclear - CNEM. CTDN Serviço de Reator e Irradiações, Rua Mário Werneck, s/n - CampusUFMG - Pampulha. CEP 30123-970.Belo Horizonte-MG.E-mail: asleal@cdtn.br.

3. Universidade Federal de Minas Gerais.

* A quem a correspondência deve ser enviada.
} 